\title{
Online Building Energy Model to Evaluate Heating and Cooling-related Behaviour Changes for Eco-feedback in a Multifamily Residential Building
}

\author{
Sang woo Ham ${ }^{1,2}$, Panagiota Karava ${ }^{1,2^{*}}$ \\ ${ }^{1}$ School of Civil Engineering Purdue University, West Lafayette, Indiana, USA \\ ${ }^{2}$ Center for High Performance Buildings, Ray W. Herrick Laboratories, Purdue University, \\ West Lafayette, Indiana, USA \\ * Corresponding Author
}

\begin{abstract}
The participation of residents plays a key role in residential energy saving strategies because they make decisions on how to operate building heating and cooling systems. Eco-feedback is an effective tool to motivate energy conserving behaviours (ECBs) by providing information on energy efficiency and associated benefits. The main purpose of this study is to develop an online data-driven building energy model to evaluate heating and cooling-related behaviour changes for eco-feedback design in a multifamily residential building. A grey-box state-space model is presented that is updated with realtime data using a particle filter approach. The model accounts for the evolution of parameters and captures the unobserved inter-unit heat transfer without modelling the whole building thermal network through sequential Bayesian update. The model is developed and validated using data collected in an actual multifamily residential building.
\end{abstract}

\section{Introduction}

While there have been various energy efficiency strategies such as advanced heating, ventilation, and airconditioning (HVAC) systems and their optimal control to reduce energy consumption and demand without compromising comfort and productivity in commercial buildings, research in residential sector is often focused on energy benchmarking (Roth \& Jain, 2018), asset ratings and cost analysis of building upgrades (Bourassa, Rainer, Mills, \& Glickman, 2012), and peak demand control (Hammerstrom et al., 2007).

The recent development of WiFi-enabled smart devices provides an opportunity to home owners to track the energy consumption associated with different devices such as heating and cooling equipment, appliances, and lighting (Ford, Pritoni, Sanguinetti, \& Karlin, 2017). However, consumption data may not be sufficient for the residents to evaluate their behaviour. Various forms of eco-feedback such as peer-comparison (Jain, Taylor, \& Peschiera, 2012), historic comparison, energy benchmarking, and setpoint scheduling (Pisharoty, Yang, Newman, \& Whitehouse, 2015) are often provided together with data to lead people towards energy-efficient behaviours (Karlin, Zinger, \& Ford, 2015).

In addition, it has been reported that explaining the benefits and providing actionable feedback can help residents understand the relative importance between various energy-related behaviours (Ehrhardt-Martinez, 2015). Thermostat control (i.e., setpoint schedule) provides opportunities for significant energy savings as heating and cooling accounts for $51 \%$ of the site energy consumption in residential houses in the U.S. (EIA, 2015) (EIA, 2015), and it has a standard form of behaviour, a setpoint schedule.

There have been many efforts on thermal modelling of houses for various applications such as optimal control (Ellis \& Alanqar, 2018), energy prediction (Siemann, 2013), etc. However, not many studies have been conducted on multifamily residential building modelling for behavioural-feedback design. One of the main challenges is the heat transfer between different units, which requires complex building-level thermal network models. In this paper, we present a novel data-driven modelling technique for multifamily residential buildings. It includes a unit-level grey-box model with online learning of parameters and hidden states through Sequential Bayesian update to account for unobserved boundary conditions and evolution of parameters.

\section{Field study}

\section{Building overview}

Our test-bed is a fully-remodelled multifamily residential building, located in Indiana, United States. The building has 49 occupied units $(40 \times 1$-bedroom and $9 \times 2$-bedroom units) located on the 2nd, 3rd, and 4th floors while one 2bedroom unit and amenities (multi-purpose room, laundry, PC room, storage rooms) are located on the 1st floor. All building materials were replaced during the remodelling except for the main concrete floor slabs, columns, and the south wall façade. The external walls and inter-unit walls include 6-inch fiberglass insulation (R19). The roof has 5-inch polyiso insulation (R30), and there is no insulation in the main concrete floor slabs. The restored south wall façade is composed of old brick without additional insulation. The apartments are aligned along the west and east side of the building and the units have windows facing west or east. Units on the west side have a balcony with sliding doors in the living room. The balconies on the 2 nd floor are located on the ground and look like a backyard (since the 1st floor is underground on the west side) while the balconies on the 3rd and 4th floors are non-protrusion type, and the units have smaller floor area. The units on the east side have operable awning windows in the living room with vinyl frame. Also, units on both east and west side have operable awning windows 
in bedrooms with vinyl frame. Each unit is conditioned with a dedicated air handler (with a heat pump outdoor unit at the rooftop) as shown in Figure 1. Although two neighbouring units share a mechanical room, the air handler is a closed-loop system, so there is no significant air mixing between units. There is R19 insulation between adjacent units but no insulation in the floor and ceiling concrete slabs except for the roof and ground. The hallway is conditioned by multiple air handlers.

Outdoor

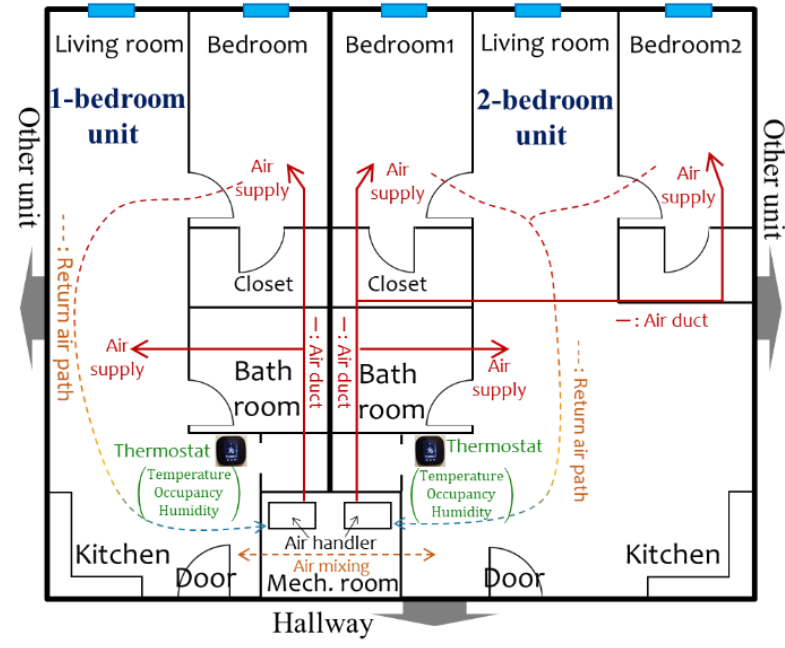

Figure 1: Room and heating/cooling system layout

In this building, Wi-Fi-enabled smart thermostats (Ecobee3, https://www.ecobee.com/) and sub-circuit power meters (GreenEye Monitor, http://www.brultech.com/greeneye/) were installed to collect disaggregated energy usage data. All smart features of the thermostats were disabled and thus, there is no functional difference besides the ability to collect measured data. Temperature, occupancy heating/cooling control signal, and setpoint data are being collected via web API to our cloud server. Power consumption is being monitored by using multiple current transformers with a WiFi-enabled sensor box. The sensor box was installed behind the electrical panel. The box is sending data to our cloud server every 30 seconds. A weather station (Davis Pro 2) was installed to monitor outdoor air temperature, humidity, and solar radiation on the rooftop. All the collected raw data is being stored into a cloud server and is uploaded after pre-processing every day. The study was approved by the Institutional Review Board (IRB Protocol \#: 1702018811).

\section{Observations}

Figure 2 shows yearly (Jan-Dec 2018) electric energy consumption data for heating and cooling along with the average temperature in each unit. Although the units are exposed to the same weather and have similar mechanical systems, floor areas, and building materials, their energy consumption shows significant variations even in the case of similar average setpoint temperatures.

In our previous work (Ham \& Karava, 2018), we have found that such variations can be explained by the differences in the locations within the building, different building characteristics as well as other disturbances such as internal heat gains. For example, a unit can be adjacent to other household units, unconditioned storage, and may have less exposed area to the ambient air if it is located in the middle or top floor of the building. Also, units have different layout (balcony door with large glazing or small windows), and thus, the required amount of heating to reach a certain setpoint can be different. To normalize these effects, in our previous work (Ham \& Karava, 2018) we proposed a Bayesian mixture model to identify groups of units that have similar building characteristics and boundary conditions. Through this approach, we can evaluate the observed energy behaviour (i.e., setpoint schedule) by comparing the energy consumption within the normalized group of data. However, this method is limited to the evaluation of past data. In this study, we present an online data-driven model to estimate the energy consumption for a potential future behaviour change.

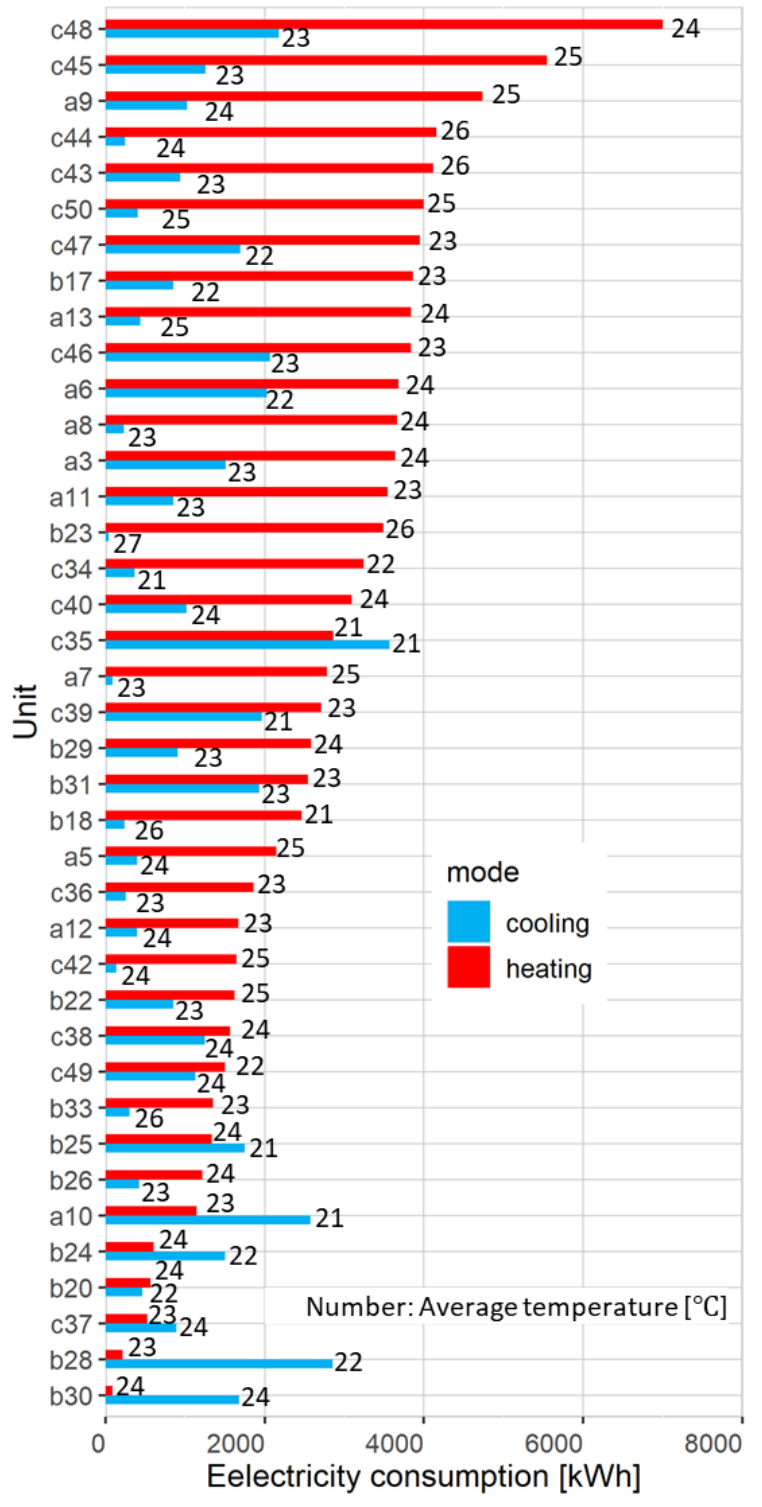

Figure 2: Yearly heating and cooling energy consumption data in different units (Jan. - Dec. 2018) 


\section{Modelling Methodology \\ Overall approach}

Heating and cooling energy consumption of a certain period is the outcome of sequential dynamical interactions of building characteristics, mechanical system operation with control input (i.e., setpoint schedule), weather, and internal heat gains (e.g., body heat, appliance use, etc.). To answer the question of how much energy is consumed for heating and cooling given a behavioural intervention, i.e., the setpoint schedule, all other variables need to be sequentially estimated for the future evaluation period. Since the building characteristics of each unit vary according to the location and boundary conditions (adjacent spaces), it is difficult to make reliable future predictions with new setpoint scenarios using a black-box model for a dynamical system. Even if we capture the physical processes through a grey-box model, the unobserved boundary conditions (i.e., temperature of neighbouring spaces) are hard to be captured unless the model includes all spaces in a building. Finally, it is necessary to calibrate model multiple times with different dataset to identify season-dependent parameters such as efficiency of heat pump for cooling, heating, and defrost operation.

Therefore, we chose a unit-level grey-box structure with online-parameter learning filter. Previous studies (Alam, Rogers, Scott, Ali, \& Auffenberg, 2018; Fux, Ashouri, Benz, \& Guzzella, 2014; Radecki \& Hencey, 2012) applied various Kalman filters for a grey-box building thermal model by augmenting parameters to the statespace (Simon, 2006). In this model, both parameters and states are filtered (i.e., prediction and then update) in realtime according to their noise variances when new data come in through Bayes rule, and this structure of model can provide uncertainties in the prediction by quantifying the posterior of hidden states. However, the posterior of parameters can diffuse because the variance of parameters would accumulate for every filtering step (Liu \& West, 2001). In other words, the one-step ahead filtering of parameters with diffused variance can end up with incorrect values and predictions. Furthermore, they become worse if the filter starts with wrong initial distributions of parameters.

To overcome this limitation, we adopt two strategies: (1) the variances of parameters need to be corrected for every filtering step, and (2) the parameter filter needs to start with good initial values. We choose Liu-West particle filter (Liu \& West, 2001) to correct the diffusion of variance, and the initial condition of parameters are estimated through a system identification technique.

The overall process of our online model is shown in Figure 3. First, the initial values of building physical parameters are obtained using a system identification technique (i.e., optimize parameters to minimize prediction errors). Once the initial parameter values are identified, then they are updated with new data by using the Liu-West particle filter (Liu \& West, 2001). After the parameter update, next week's energy consumption is predicted based on a scenario for a future behaviour change (i.e., new setpoint schedule).

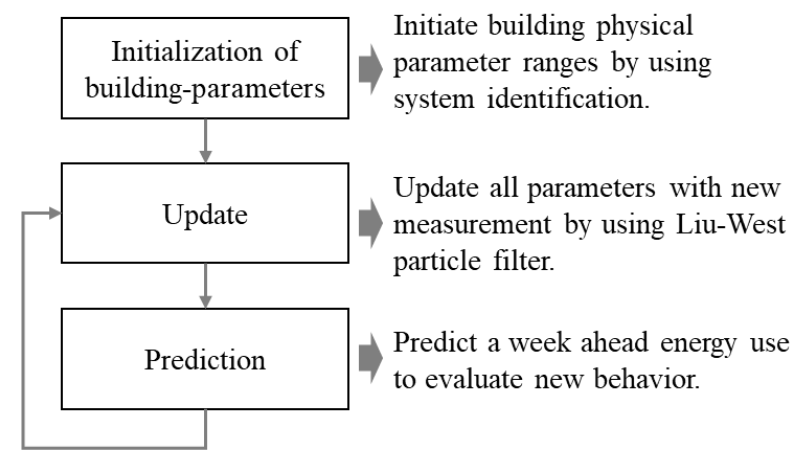

Figure 3: Model Process

\section{Model structure}

A grey-box model structure (Figure 4) is used to model one household unit in the building. All variables are described in Table 1.

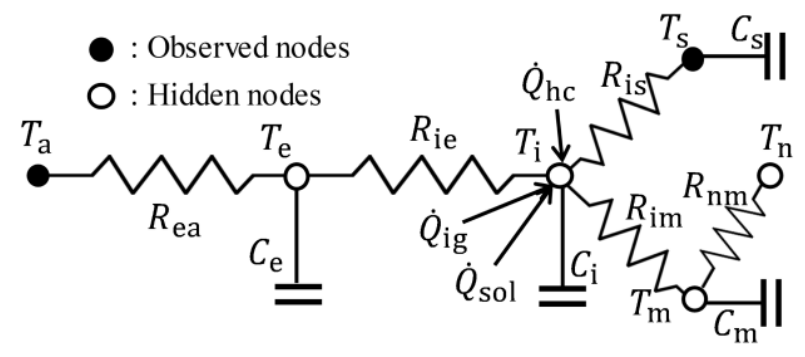

Figure 4: Model structure

Table 1: Variables and parameters in a model

\begin{tabular}{|c|c|}
\hline Name & Description \\
\hline$T_{\mathrm{a}}\left[{ }^{\circ} \mathrm{C}\right]$ & Outdoor air temperature \\
\hline$T_{\mathrm{i}}\left[{ }^{\circ} \mathrm{C}\right]$ & Indoor air temperature \\
\hline$T_{\mathrm{e}}, T_{\mathrm{m}}$ & $\begin{array}{c}\text { Exterior wall, interior mass, and thermostat } \\
T_{\mathrm{S}}\left[{ }^{\circ} \mathrm{C}\right]\end{array}$ \\
\hline$T_{\mathrm{n}}\left[{ }^{\circ} \mathrm{C}\right]$ & Ovensor temperature \\
\hline$y_{T_{\mathrm{s}}}\left[{ }^{\circ} \mathrm{C}\right]$ & Measured thermostat sensor temperature \\
\hline$R_{\mathrm{ea}}, R_{\mathrm{ie}}, R_{\mathrm{in}}$ & Thermal resistance between temperature \\
$R_{\mathrm{nm}}, R_{\mathrm{is}}[\mathrm{k} / \mathrm{W}]$ & nodes \\
\hline$C_{\mathrm{e}}, C_{\mathrm{i}}, C_{\mathrm{m}}$ & Thermal capacitance of each node \\
$C_{\mathrm{S}}[\mathrm{J} / \mathrm{K}]$ & Solar gains through glazing \\
\hline$\dot{Q}_{\mathrm{sol}}[\mathrm{W}]$ & Internal device heat gain \\
\hline$\dot{Q}_{\mathrm{ig}}[\mathrm{W}]$ & Heat/Cool supply rate from the heating and \\
\hline$\dot{Q}_{\mathrm{hc}}[\mathrm{W}]$ & cooling device \\
\hline
\end{tabular}

The model (Figure 4) can be expressed as a set of differential equations for the state $(\mathbf{x})$ transition (Eq. 1) and observation $(y)$ without noise (Eq. 2).

$$
\begin{gathered}
\dot{\mathbf{x}}(t)=\mathbf{A} \mathbf{x}(t)+\mathbf{B u}(t) \\
y(t)=\mathbf{C} \mathbf{x}(t) \\
\mathbf{x}(t)=\left[T_{\mathrm{e}}(t), T_{\mathrm{i}}(t), T_{\mathrm{m}}(t), T_{\mathrm{s}}(t), T_{\mathrm{n}}(t)\right]^{\mathrm{T}} \\
y(t)=\left[y_{T_{\mathrm{s}}}(t)\right] \\
\mathbf{u}(t)=\left[T_{a}(t), \dot{Q}_{\mathrm{sol}}(t), \dot{Q}_{\mathrm{ig}}(t), \dot{Q}_{\mathrm{cal}, \mathrm{hc}}(t)\right]^{\mathrm{T}}
\end{gathered}
$$




$$
\begin{gathered}
\mathbf{A}=\left[\begin{array}{ccccc}
\frac{-1}{R_{\mathrm{ea}} C_{\mathrm{e}}}+\frac{-1}{R_{\mathrm{ie}} C_{\mathrm{e}}} & \frac{1}{R_{\mathrm{ie}} C_{\mathrm{e}}} & 0 & 0 & 0 \\
\frac{1}{R_{\mathrm{ie}} C_{\mathrm{i}}} & A_{22} & \frac{1}{R_{\mathrm{im}} C_{\mathrm{i}}} & \frac{1}{R_{\mathrm{is}} C_{\mathrm{i}}} & 0 \\
0 & \frac{1}{R_{\mathrm{im}} C_{\mathrm{m}}} & A_{33} & 0 & \frac{1}{R_{\mathrm{nm}} C_{\mathrm{m}}} \\
0 & \frac{1}{R_{\mathrm{is}} C_{\mathrm{s}}} & 0 & \frac{-1}{R_{\mathrm{is}} C_{\mathrm{s}}} & 0 \\
0 & 0 & 0 & 0 & 0
\end{array}\right] \\
A_{22}=\frac{-1}{R_{\mathrm{ie}} C_{\mathrm{i}}}+\frac{-1}{R_{\mathrm{im}} C_{\mathrm{i}}}+\frac{-1}{R_{\mathrm{is}} C_{\mathrm{i}}}, A_{33}=\frac{-1}{R_{\mathrm{im}} C_{\mathrm{m}}}+\frac{-1}{R_{\mathrm{nm}} C_{\mathrm{m}}}
\end{gathered}
$$

$$
\begin{gathered}
\mathbf{B}=\left[\begin{array}{cccc}
\frac{1}{R_{\mathrm{ea}} C_{\mathrm{e}}} & 0 & 0 & 0 \\
0 & \frac{A_{\mathrm{w}}}{C_{\mathrm{i}}} & \frac{\eta_{\mathrm{ig}}}{C_{\mathrm{i}}} & 0 \\
0 & 0 & 0 & 0 \\
0 & 0 & 0 & \frac{\eta_{\mathrm{hc}}(t)}{C_{\mathrm{s}}} \\
0 & 0 & 0 & 0
\end{array}\right] \\
\mathbf{C}=\left[\begin{array}{lllcc}
0 & 0 & 0 & 1 & 0 \\
0 & 0 & 0 & 0 & 0
\end{array}\right]
\end{gathered}
$$

In our model, the incoming solar radiation $\left(\dot{Q}_{\text {sol }}(t)=\right.$ $\left.A_{W} \dot{Q}_{\text {rad }}(t)\right)$ is modelled with a single parameter $\left(A_{w}\right)$. $\dot{Q}_{\text {rad }}(t)$ is the global horizontal irradiance at the weather station, and $A_{w}$ includes the overall effective window area and its solar heat gain coefficient. The actual heat flow rate $\left(\dot{Q}_{\mathrm{hc}}(t)\right)$ is calculated by multiplying a constant efficiency parameter $\left(\eta_{h c}(t)\right)$ to the calculated heat flow rate $\left(\dot{Q}_{\text {cal,hc }}(t)\right) \cdot \dot{Q}_{\text {cal,hc }}(t)$ is the calculated heat flow rate of heating/cooling system from the measured power consumption data. We use calculated values because we do not measure the actual heating/cooling rate but a sequence of binary signals along with the power consumption of the heat pump system. The heating/cooling system in our test-bed has 4 operation modes: (1) heat pump heating (htg), (2) auxiliary heating (aux), (3) heat pump heating with defrost cycle (df), and (4) heat pump cooling (clg). The operation mode $\left(i_{\mathrm{hc}}(t) \in\{\mathrm{htg}\right.$, aux, df, clg $\left.\}\right)$ is decided based on the thermostat setting and outdoor air condition.

$$
\eta_{\mathrm{hc}}(t)= \begin{cases}\eta_{\mathrm{htg}} & \text { if } i_{\mathrm{hc}}(t)=\mathrm{htg} \\ \eta_{\mathrm{aux}} & \text { if } i_{\mathrm{hc}}(t)=\mathrm{aux} \\ \eta_{\mathrm{df}} & \text { if } i_{\mathrm{hc}}(t)=\mathrm{df} \\ \eta_{\mathrm{clg}} & \text { if } i_{\mathrm{hc}}(t)=\mathrm{clg}\end{cases}
$$

The actual heat flow rates $\left(\dot{Q}_{\mathrm{hc}}(t)\right)$ are:

$$
\left\{\begin{array}{c}
\dot{Q}_{\mathrm{htg}}=\eta_{\mathrm{htg}} \dot{Q}_{\mathrm{cal}, \mathrm{htg}}=\eta_{\mathrm{htg}} k_{\mathrm{htg}} \mathrm{COP}_{\mathrm{htg}} P_{\text {nom }, \mathrm{htg}} \\
\dot{Q}_{\mathrm{aux}}=\eta_{\mathrm{aux}} \dot{Q}_{\mathrm{cal}, \mathrm{aux}}=\eta_{\mathrm{aux}} k_{\mathrm{aux}} P_{\mathrm{nom}, \mathrm{aux}} \\
\dot{Q}_{\mathrm{df}}=\eta_{\mathrm{df}} \dot{Q}_{\mathrm{df}}=\eta_{\mathrm{df}}\left(k_{\mathrm{aux}, \mathrm{df}} P_{\mathrm{nom}, \mathrm{aux}}+k_{\mathrm{htg}, \mathrm{df}} \mathrm{COP}_{\mathrm{htg}} P_{\text {nom }, \mathrm{htg}}\right) \\
\dot{Q}_{\mathrm{clg}}=\eta_{\mathrm{clg}} \dot{Q}_{\mathrm{clg}}=\eta_{\mathrm{clg}} k_{\mathrm{clg}} \operatorname{COP}_{\mathrm{clg}} P_{\text {nom,clg }}
\end{array}\right.
$$

where $P_{\text {nom,htg }}, P_{\text {nom,clg }}$, and $P_{\text {nom,aux }}$ are nominal power of heat pump heating, heat pump cooling, and auxiliary heating. $k_{\mathrm{htg}}, k_{\mathrm{aux}}, k_{\mathrm{df}}$ and $k_{\mathrm{clg}}$ are effectiveness times part-time-load factor ratio. $k \times P_{\text {nom }}$ is the measured power, which is used to predict the power consumption given a setpoint change. $\mathrm{COP}_{\text {htg }}$ and $\mathrm{COP}_{\text {clg }}$ are the coefficient of performance values of heat pump for heating and cooling respectively. This is acquired from manufacturer's catalogue data and modeled as a linear function of outdoor air temperature $\left(T_{\mathrm{a}}\right)$.

The continuous system $[\mathbf{A}(\boldsymbol{\theta}), \mathbf{B}(\boldsymbol{\theta}), \mathbf{C}(\boldsymbol{\theta})]$ is discretized $\left[\mathbf{A}_{\mathrm{d}}\left(\boldsymbol{\theta}_{\mathrm{d}}\right), \mathbf{B}_{\mathrm{d}}\left(\boldsymbol{\theta}_{\mathrm{d}}\right), \mathbf{C}_{\mathrm{d}}\left(\boldsymbol{\theta}_{\mathrm{d}}\right)\right]$ using 5-minute time-step where $\left(\boldsymbol{\theta}=\left\{C_{\mathrm{e}}, C_{\mathrm{m}}, C_{\mathrm{i}}, C_{\mathrm{h}}, R_{\mathrm{ea}}, R_{\mathrm{im}}, R_{\mathrm{ie}}, R_{\mathrm{ih}}, A_{\mathrm{w}}, k_{\mathrm{ig}}\right.\right.$, $\left.\left.k_{\mathrm{htg}}, k_{\mathrm{aux}}, k_{\mathrm{df}}, k_{\mathrm{clg}}, \sigma_{x}, \sigma_{y}\right\}\right)$. Then, the discrete statespace model can be expressed as the following probabilistic form (Eqs. 11-14) with noise parameters $\left(\boldsymbol{\sigma}_{x}, \sigma_{y}\right)$. Here, measurement error noise $\sigma_{\mathrm{y}}$ is set to $0.5^{\circ} \mathrm{F}$ according to thermostat sensor accuracy.

$$
\begin{gathered}
\operatorname{Pr}\left(\mathbf{x}_{t+1} \mid \mathbf{x}_{t}\right)=\mathcal{N}\left(\mathbf{x}_{t+1} \mid f\left(\mathbf{x}_{t}, \mathbf{u}_{t}, \boldsymbol{\theta}_{\mathrm{d}}\right), \boldsymbol{\sigma}_{x}\right) \\
\operatorname{Pr}\left(y_{t} \mid \mathbf{x}_{t}\right)=\mathcal{N}\left(y_{t} \mid g\left(\mathbf{x}_{t}, \mathbf{u}_{t}, \boldsymbol{\theta}_{\mathrm{d}}\right), \sigma_{y}\right) \\
f\left(\mathbf{x}_{t}, \mathbf{u}_{t}, \boldsymbol{\theta}_{\mathrm{d}}\right)=\mathbf{A}_{\mathrm{d}} \mathbf{x}_{t}+\mathbf{B}_{\mathrm{d}} \mathbf{u}_{t} \\
g\left(\mathbf{x}_{t}, \boldsymbol{\theta}_{\mathrm{d}}\right)=\mathbf{C}_{d} \mathbf{x}_{t}
\end{gathered}
$$

\section{Initial parameter learning}

For a discrete state-space model, the expectation of $t$-step ahead prediction $\left(\mathbf{x}_{t \mid 1: t-1}\right.$ and $\left.y_{t \mid 1: t-1}\right)$ can be sequentially estimated through Eqs. 15 and 16 from $\mathbf{x}_{1}$ and $y_{1}$.

$$
\begin{gathered}
\mathbb{E}\left[\mathbf{x}_{t \mid 1: t-1} \mid \mathbf{x}_{t-1 \mid 1: t-2}, \mathbf{u}_{t-1}\right]=f\left(\mathbf{x}_{t-1 \mid 1: t-2}, \mathbf{u}_{t-1}, \boldsymbol{\theta}_{\mathrm{d}}\right) \\
=\mathbf{A}_{\mathrm{d}} \mathbf{x}_{t-1 \mid 1: t-2}+\mathbf{B}_{\mathrm{d}} \mathbf{u}_{t-1} \\
\mathbb{E}\left[\mathbf{y}_{t} \mid \mathbf{x}_{t \mid 1: t-1}\right]=g\left(\mathbf{x}_{t \mid 1: t-1}, \boldsymbol{\theta}_{\mathrm{d}}\right)=\mathbf{C}_{\mathrm{d}} \mathbf{x}_{t \mid 1: t-1}
\end{gathered}
$$

The $t$-step ahead predictions with unknown state values are compared with measured data. The initial parameters are found based on the minimization of the sum of square errors (Eq. 17). Sets of parameters are obtained by using a differential evolutionary global optimization method with random initialization (Mullen, Ardia, Gil, Windover, $\&$ Cline, 2011). The best parameter set is chosen by calculating the same $t$-step ahead prediction for next week's data.

$$
\boldsymbol{\theta}_{\mathrm{d}, \text { init }}=\arg \min _{\boldsymbol{\theta}_{\mathbf{d}}} \sum_{t=2}^{N}\left[\mathbb{E}\left[y_{t} \mid \mathbf{x}_{\mathrm{t} \mid 1: t-1}, \mathbf{u}_{1: t}\right]-y_{t}\right]^{2}
$$

In the Table 2, the bounds of parameter range and the estimation results are shown. The solutions of Eq. 17 are not unique according to their starting points though the optimization results are similar. Thus, we repeated the optimization 50 times and calculated the ranges that were used to generate initial particles for the Liu-West filter. The mean values are chosen based on best prediction for next week's data while the ranges are acquired from the other solutions. 
Table 2: Parameter values (SI unit in parenthesis)

\begin{tabular}{|c|c|c|c|}
\hline Parameter $(\theta, \zeta)$ & $\begin{array}{l}\text { Lower } \\
\text { bound }\end{array}$ & $\begin{array}{l}\text { Upper } \\
\text { bound }\end{array}$ & $\begin{array}{c}\text { Estimation result } \\
(\text { Mean } \pm \mathrm{SD})\end{array}$ \\
\hline$T_{e 0}\left[{ }^{\circ} \mathrm{F}\right]\left({ }^{\circ} \mathrm{C}\right)$ & $30(-1)$ & $70(21.1)$ & $30 \pm 10(-1 \pm 5.5)$ \\
\hline $\begin{array}{c}T_{\mathrm{i} 0}, T_{\mathrm{m} 0}, T_{\mathrm{s} 0}, T_{n} \\
{\left[{ }^{\circ} \mathrm{F}\right]\left({ }^{\circ} \mathrm{C}\right)}\end{array}$ & $\begin{array}{c}50 \\
(15.5)\end{array}$ & $\begin{array}{c}80 \\
(26.7)\end{array}$ & $\begin{array}{c}73 \pm 5(22.8 \pm 2.78) \\
74.5 \pm 5(23.6 \pm 2.78) \\
72 \pm 5(22.2 \pm 2.78) \\
72 \pm 5(22.2 \pm 2.78)\end{array}$ \\
\hline$C_{\mathrm{e}}[\mathrm{BTU} / \mathrm{F}](\mathrm{kJ} / \mathrm{K})$ & $\begin{array}{c}100 \\
(190)\end{array}$ & $\begin{array}{c}10000 \\
(19000) \\
\end{array}$ & $1850 \pm 200(3513 \pm 380)$ \\
\hline$C_{\mathrm{i}}[\mathrm{BTU} / \mathrm{F}](\mathrm{kJ} / \mathrm{K})$ & $\begin{array}{c}5 \\
(9.49) \\
\end{array}$ & \begin{tabular}{|c|}
5000 \\
$(9495)$ \\
\end{tabular} & $1050 \pm 200(1995 \pm 380)$ \\
\hline$C_{\mathrm{m}}[\mathrm{BTU} / \mathrm{F}](\mathrm{kJ} / \mathrm{K})$ & \begin{tabular}{|c|}
25000 \\
$(47477)$ \\
\end{tabular} & $\begin{array}{c}65000 \\
(123441) \\
\end{array}$ & $\begin{array}{l}35000 \pm 10000 \\
(66468 \pm 18991)\end{array}$ \\
\hline$C_{\mathrm{s}}[\mathrm{BTU} / \mathrm{F}](\mathrm{kJ} / \mathrm{K})$ & \begin{tabular}{|c|}
5 \\
$(9.5)$ \\
\end{tabular} & \begin{tabular}{|c|}
500 \\
$(950)$
\end{tabular} & $400 \pm 50(759 \pm 95)$ \\
\hline $\begin{array}{c}R_{\mathrm{ea}}, R_{\mathrm{ie}} \\
{[\mathrm{F} \cdot \mathrm{S} / \mathrm{BTU}](\mathrm{K} / \mathrm{kW})}\end{array}$ & $\begin{array}{c}5 \\
(2.6) \\
\end{array}$ & $\begin{array}{c}100 \\
(52.6)\end{array}$ & $\begin{array}{c}20 \pm 5(10.5 \pm 2.6) \\
60 \pm 10(31.6 \pm 5.3) \\
\end{array}$ \\
\hline $\begin{array}{c}R_{\mathrm{is}}, R_{\mathrm{im}}, R_{\mathrm{n}} \\
{[\mathrm{F} \cdot \mathrm{S} / \mathrm{BTU}](\mathrm{K} / \mathrm{kW})}\end{array}$ & $\left|\begin{array}{c}1 e-4 \\
(5.2 \cdot 1 e-5)\end{array}\right|$ & $\begin{array}{c}10 \\
(5.26) \\
\end{array}$ & $\begin{array}{c}5 \pm 2(2.6 \pm 1) \\
0.025 \pm 0.01(0.013 \pm 0.005) \\
2.5 \pm 1(1.3 \pm 0.5) \\
\end{array}$ \\
\hline$A_{\mathrm{w}}[-]$ & 0 & 1 & \begin{tabular}{|l|}
$0.03 \pm 0.005$ \\
\end{tabular} \\
\hline $\begin{array}{c}\eta_{\text {ig }}, \eta_{\text {htg }}, \eta_{\text {aux }} \\
\eta_{\text {df }}, \eta_{\mathrm{clg}}[-] \\
\end{array}$ & 0 & 1 & $\begin{array}{c}\eta_{\text {ig }}: 0.55 \pm 0.1 \\
\text { Others: } 0.3 \pm 0.05 \\
\end{array}$ \\
\hline
\end{tabular}

\section{Particle filter update}

Liu-west filter (Liu \& West, 2001) is one type of particle filter (i.e., Sequential Monte Carlo method), which updates the posterior of state variables at current time $(t)$ based on previous data $(1: t-1)$ but is also capable of updating the parameters at the same time (Liu \& West, 2001). The joint distribution of state variables and parameters $\left(\operatorname{Pr}\left(\mathbf{x}_{t}, \boldsymbol{\theta} \mid \mathbf{y}_{1: t}\right)\right)$ is updated on every iteration from the previous data (Eq. 18).

$$
\begin{array}{r}
\operatorname{Pr}\left(\mathbf{x}_{t}, \boldsymbol{\theta} \mid \mathbf{y}_{1: t}\right) \propto \operatorname{Pr}\left(\mathbf{y}_{1: t} \mid \mathbf{x}_{t}, \boldsymbol{\theta}\right) \operatorname{Pr}\left(\mathbf{x}_{t}, \boldsymbol{\theta} \mid \mathbf{y}_{1: t-1}\right) \\
\propto \operatorname{Pr}\left(\mathbf{y}_{1: t} \mid \mathbf{x}_{t}, \boldsymbol{\theta}\right) \operatorname{Pr}\left(\mathbf{x}_{t} \mid \mathbf{y}_{1: t-1}, \boldsymbol{\theta}\right) \operatorname{Pr}\left(\boldsymbol{\theta} \mid \mathbf{y}_{1: t-1}\right)
\end{array}
$$

While the total $N$ number of state particles $\left(\mathbf{x}_{t}^{(1: N)}\right)$ are updated through the auxiliary particle filtering method with sampling weight $\left(\pi_{t}^{(1: N)}\right)$, the parameters of each particle $\left(\boldsymbol{\theta}_{t}^{(n)}\right)$ are updated by adding noise $\left(\zeta_{t}^{(n)}\right)$ generated by zero mean gaussian with diagonal noise matrix $\left(\mathbf{W}_{t}\right)($ Eq. 19).

$$
\begin{gathered}
\boldsymbol{\theta}_{t}^{(n)}=\boldsymbol{\theta}_{t-1}^{(n)}+\zeta_{t}^{(n)} \\
\zeta_{t}^{(n)} \sim \mathcal{N}\left(\mathbf{0}, \mathbf{W}_{t}\right)
\end{gathered}
$$

However, putting the parameters into the state vector ends up with diffused variance, so the variance needs to be corrected so that $\operatorname{Var}\left(\boldsymbol{\theta}_{t+1} \mid y_{1: t}\right)=\operatorname{Var}\left(\boldsymbol{\theta}_{t} \mid y_{1: t}\right)=\mathbf{V}_{\boldsymbol{\theta}, t}$. By approximating the marginal posterior of parameter distribution $\left(\operatorname{Pr}\left(\boldsymbol{\theta}_{t} \mid y_{1: t-1}\right)\right)$ using a multivariate normal gaussian kernel, the parameters can be updated as Eq. 20.

$$
\begin{aligned}
& \operatorname{Pr}\left(\boldsymbol{\theta}_{t} \mid \mathbf{y}_{1: t-1}\right) \approx \\
& \sum_{i=1}^{N} w_{t-1}^{(i)} \mathcal{N}\left(\boldsymbol{\theta}_{t} \mid \boldsymbol{\mu}_{\boldsymbol{\theta}, t \mid t-1}^{(i)},\left(\boldsymbol{I}-\mathbf{S}_{\boldsymbol{\theta}, t}^{2}\right) \mathbf{V}_{\boldsymbol{\theta}, t-1}\right)
\end{aligned}
$$

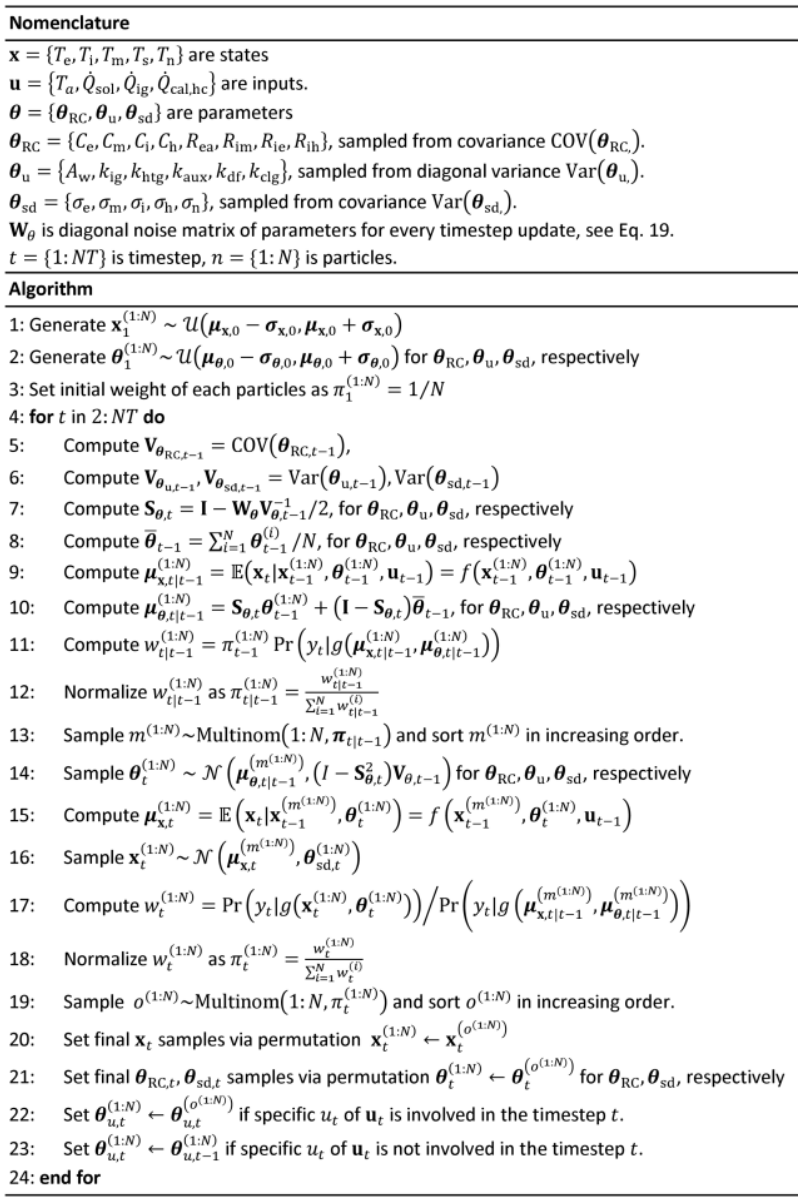

Figure 5. Modified Liu-West Algorithm for onlinebuilding model

The details of calculation are shown in Figure 5. In this research, the original algorithm is slightly modified as follows:

(1) We split the building physical parameters $\left(\boldsymbol{\theta}_{\mathrm{RC}}\right)$, input-related parameters $\left(\boldsymbol{\theta}_{\mathrm{u}}\right)$, and standard deviationrelated parameters $\left(\boldsymbol{\theta}_{\mathrm{sd}}\right)$, and then, $\boldsymbol{\theta}_{\mathrm{RC}}$ are sampled from the covariance of previous values of all parameters while the others $\left(\boldsymbol{\theta}_{\mathrm{u}}, \boldsymbol{\theta}_{\mathrm{sd}}\right)$ are sampled from the variance of each parameter as shown in Figure 5. It should be noted that $\boldsymbol{\theta}_{\mathrm{RC}}$ are related to each other through the heat transfer process in each timestep while $\boldsymbol{\theta}_{\mathrm{u}}$ are not always dependent to each other as $\mathbf{u}$ are not always involved in the process at every timestep.

(2) For the same reason, $\boldsymbol{\theta}_{\mathrm{u}}$ are not always updated as shown in line 22 and 23 of Figure 5. For example, during the heating process, $k_{\mathrm{clg}}$ should not be updated.

(3) We use a fixed noise matrix for parameter updates to specify the update ranges of each timestep as 5\% and $10 \%$ of parameters' standard deviations.

$$
\mathbf{W}_{\boldsymbol{\theta}_{\mathrm{RC}, \mathrm{u}}, t}=\operatorname{diag}\left(\mathbf{0 . 0 5 ^ { 2 }}\right), \mathbf{W}_{\boldsymbol{\theta}_{\mathrm{sd}}, t}=\operatorname{diag}\left(\mathbf{0 . 1 ^ { 2 }}\right)
$$

We subtract the mean and divide by the standard deviation (Table 2) to the real parameter values so that they are sampled from similar gaussian distribution. Although the original algorithm (Liu \& West, 2001) derived a simplified version of variance update/correction rule by using a single discounting factor, we use the original 
update rule with $\mathbf{W}_{\boldsymbol{\theta}}$ (line 7, 14 in Figure 5) to specify update ranges (Eq. 21).

(4) When there is missing data in $y_{\mathrm{t}}$ or $\mathbf{u}_{t}, \mathbf{x}_{t}$ and $\boldsymbol{\theta}_{t}$ particles are not updated until new data comes in.

\section{Prediction}

Figure 6 is a schematic diagram of the prediction process with this model. With the recent states and updated parameters from the particle filter, the next week's energy consumption is predicted based on a proposed setpoint schedule and weather forecast.

In this model, the heating and cooling operation signal $\left(i_{\mathrm{hc}}(t)\right)$ is decided every time step based on the setpoint and the predicted indoor temperature $\left(T_{\mathrm{i}}\right)$ at the current timestep. The thermostat model is composed of multiple if-then-else rules, and some key rules in our thermostat are outlined below:

- Heat pump heating is disabled when outdoor temperature is lower than $5^{\circ} \mathrm{F}\left(-15^{\circ} \mathrm{C}\right)$.

- Auxiliary electric heating is disabled when outdoor air temperature is higher than $55^{\circ} \mathrm{F}\left(12.8^{\circ} \mathrm{C}\right)$.

- When the setpoint is not met for 30 minutes with heatpump heating, the auxiliar heating is activated.

- When outdoor temperature is lower than $32^{\circ} \mathrm{F}\left(0^{\circ} \mathrm{C}\right)$, the deforst cycle is activated. But, the cycling interval is determined by sensor in outdoor unit.

- The minimum heatpump cycling time is 5 minute.

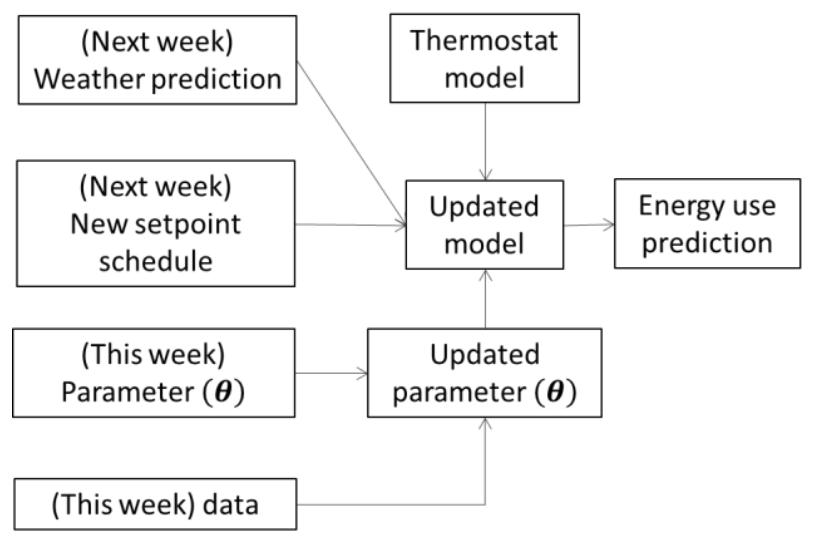

Figure 6:Prediction process

\section{Modelling results}

\section{Initial parameter learning}

One-week (2018/01/22-2018/01/28) training data of one household unit with outdoor conditions ranging from 30 to $50^{\circ} \mathrm{F}$ is selected for learning the initial buildingphysical parameters (Table 2). With the bounds shown in Table 2, we run the optimizer to get initial ranges of parameters with 50 random initial starting points to minimize the objective function (Eq. 17). The best set of parameters are chosen based on the temperature prediction for next five days (2018/01/29-2018/02/02). The best set is used as the mean of the initial parameters, and the other sets are used to specify the ranges as shown in Table 2. Figure 7 presents a comparison of predicted indoor temperature $\left(T_{\mathrm{i}}\right)$ and measured data $\left(y_{T_{\mathrm{i}}}\right)$ based on the initial parameters. The left side (2018/01/222018/01/28) corresponds to the training period, and the results show good agreement with measured data. The right side (2018/01/29-2018/02-02) is the prediction period. Although the model captures the overall temperature profile of the building response, oscillations with an average of $1^{\circ} \mathrm{C}$ are observed. Unobserved disturbances such as infiltration or human body heat could be associated with this discrepancy, but the overall temperature of neighbouring spaces $\left(T_{\mathrm{n}}\right)$ (yellow line) it is expected to be the main cause because it is identified as a single constant and not updated.

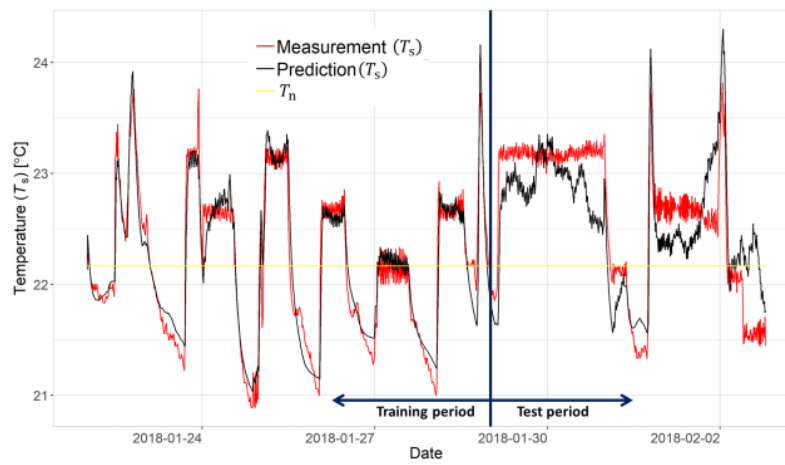

Figure 7: Temperature prediction in training period

\section{Particle filter}

With initial parameter ranges, 10000 particles of parameter and state samples are generated and updated on new data through Liu-West Particle filter. Figure 8 shows the particle filter update for the beginning of the dataset. The distribution of filtered sensor temperature state $\left(T_{\mathrm{s}}\right)$ $(2.5,50$, and $97.5 \%$ quantiles with blue and black lines) is shown with measured data. Since the filter starts with good initial parameters, the filtered state is in good agreement with the measured data. In addition, the median profile of interior mass $\left(T_{\mathrm{m}}\right)$ and overall neighbouring space $\left(T_{\mathrm{n}}\right)$ temperature states are shown with the green and yellow line, respectively. One of the advantages of filter is the update of states distribution every time step. Specifically, in this model (Eqs. 11-14), $T_{\mathrm{n}}$ is modelled as unobserved fixed temperature for each time step. However, its value would change for the next time step. By updating the state distribution with new data, the filter identifies the unobserved changes of $T_{n}$ as shown in the yellow line of Figure 8.

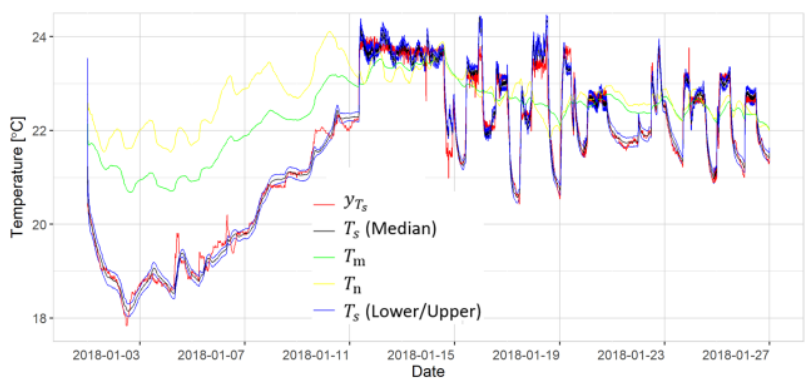

Figure 8. Particle filter for states

Figure 9 shows as an example the update process for one parameter distribution $\left(R_{\mathrm{ea}}\right)$. From the initial parameter range, the samples are updated through the filter. This can 
be viewed as posterior distribution of parameter with the data before the current time step (Eq. 18).

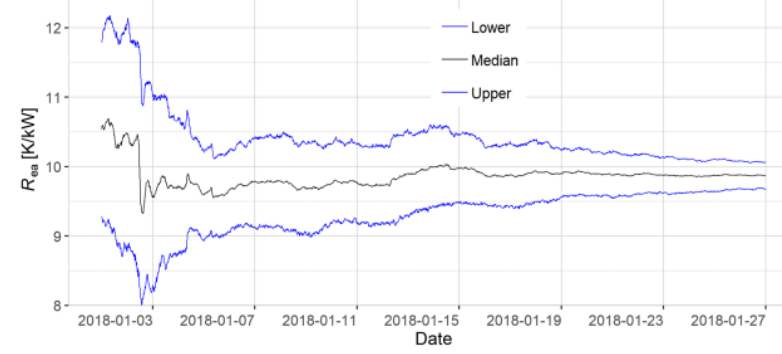

Figure 9. Particle filter for parameter update

\section{Parameter learning for cooling operation}

The particle filter is online model, so it can learn new parameters. Figure 10 shows the learning process of cooling efficiency parameter $\left(\eta_{\text {clg }}\right)$. As the initial parameters are learned from the heating season, we do not have information regarding $\eta_{\mathrm{clg}}$. In April, the green period (1) in Figure 10 shows the first cooling operation of the year in this unit. During period (1), the distribution is significantly different, and then it slowly changes in period (2).

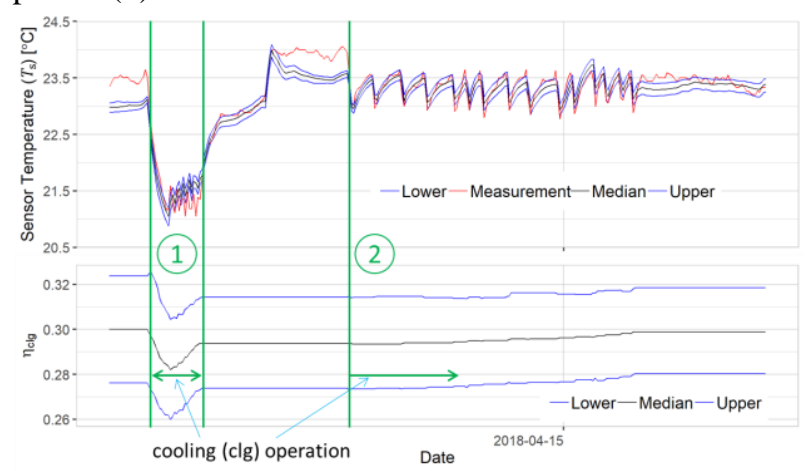

Figure 10. Learning new parameter $\left(\eta_{c l g}\right)$

\section{Approximation of future $\boldsymbol{T}_{\boldsymbol{n}}$}

In Figure 8, the particle filter can identify unobserved profiles of the overall neighbouring space temperature $\left(T_{\mathrm{n}}\right)$. However, the profiles are historic, and thus, it is necessary to predict future profiles. Since this is the result from the complex thermal dynamics of multiple household units with different settings and behaviours, it is impossible to predict the exact profiles for the future without information from all the spaces in the building. However, this temperature profile is related to the unit's sensor temperature $\left(T_{\mathrm{s}}\right)$ because the changes in unit's temperature would affect neighbouring spaces' temperature, too. Considering the impact of neighbouring spaces to the unit is a slow process due to the large internal mass $\left(C_{\mathrm{m}}\right)$ and changes in $T_{\mathrm{n}}$ within small ranges during the whole season (i.e., $21-24^{\circ} \mathrm{C}$ ). However, we can approximate $\widehat{T}_{\mathrm{n}}$ with $\widehat{T}_{\mathrm{s}}$. Figure 11 shows the relationship between identified $T_{\mathrm{n}}$ and $T_{\mathrm{s}}$ for one household via particle filter during Jan-Aug 2018. Although there are variations, they show a clear positive correlation. Thus, we use a linear function to approximate the relationship of predicted $\widehat{T}_{\mathrm{n}, t+1}$ by predicted $\widehat{T}_{\mathrm{s}, t+1}$ as shown in Figure 11. In other words, based on current input $\left(\mathbf{u}_{t}\right)$ and predicted states $\left(\hat{\mathbf{x}}_{t}\right)$, the next states $\hat{\mathbf{x}}_{t+1}$ are predicted first, and then $\widehat{T}_{\mathrm{n}, t+1}$ is corrected with $\widehat{T}_{\mathrm{s}, t+1}$ (Eq. 22).

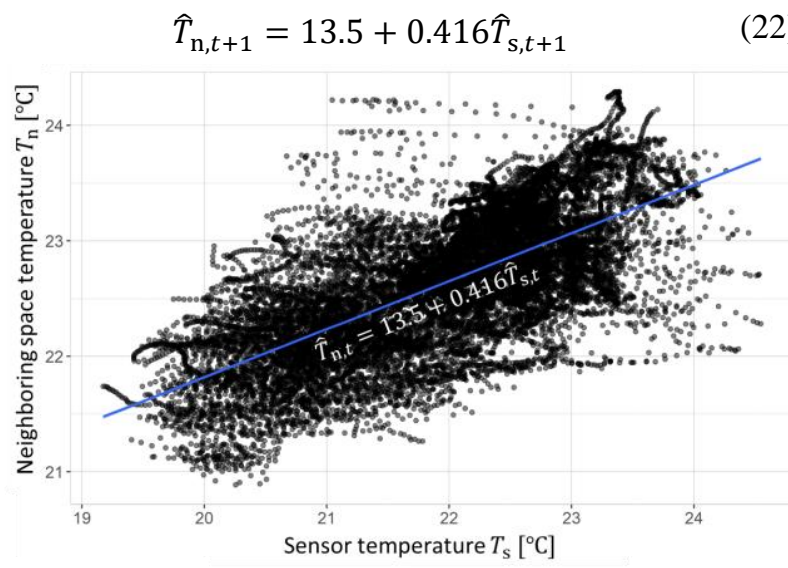

Figure 11. Approximation of neighbouring space temperature from indoor temperature

\section{Model validation via prediction}

In Figure 12, the mean temperature prediction results from the fixed model (green line, initial parameters from system identification technique) and the updated model (black line, updated parameters with particle filter) are compared. In order to visualize the effect of the online approach, we updated the model from the winter period and the compared the predictions on summer data. Both predictions start with the same filtered states from the previous week but different system parameters and neighbouring space model. For the fixed model, fixed neighbour temperature and initial parameters are used. The updated model uses an approximate model for the neighbouring space temperature and updated parameters. The fixed model's root mean squared temperature prediction error (RMSE) is $1.2^{\circ} \mathrm{C}$, which is significantly higher than the $0.35^{\circ} \mathrm{C} \mathrm{RMSE}$ of the update model.

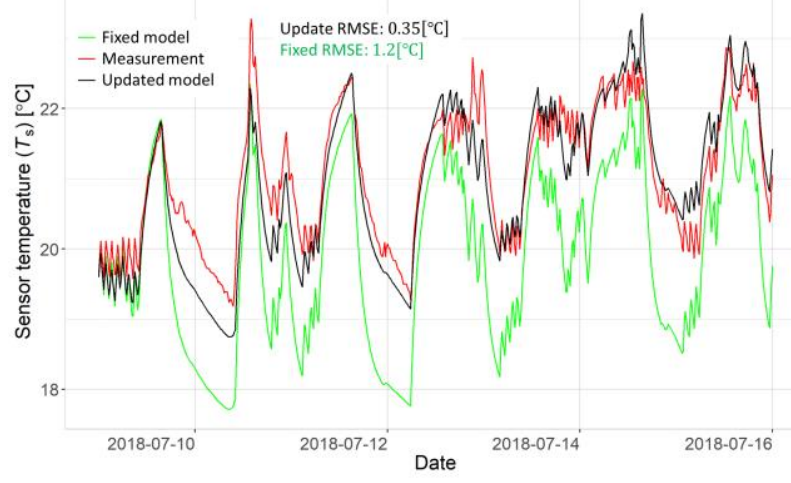

Figure 12. Comparison of updated and fixed model of mean temperature prediction for a week during summer season

\section{Eco-feedback scenario}

In future work by the authors, the developed online model will be integrated in smart user-interactive eco-feedback systems with information visualization or voice control. Such smart systems will be integrated in multi-unit residential buildings to help residents make informed decisions about their setpoint schedule considering the 
predicted energy use. In addition, this model will be considered in the design of personalized feedback messages and incentives to motivate energy conserving behaviours. In this section, we present a simple scenario to demonstrate the use of the model. With the updated model from the previous week, residents can estimate their expected energy consumption for next week if they adopt a new setpoint schedule. Figure 13 shows the predicted energy consumption from three setpoint scenarios with uncertainties. The model is updated from $2018 / 01 / 01$ to $2018 / 01 / 21$, and the energy consumption of $2018 / 01 / 21-28$ is estimated. The green distribution is the energy consumption when the residents keep using the current setpoint schedule (i.e., Home $23.3^{\circ} \mathrm{C}$, Away $\left.21.7^{\circ} \mathrm{C}\right)$. The vertical line $(63 \mathrm{kWh})$ is the measured power consumption of this period, and the prediction results are 63.5-69.8kWh (2.5-97.5\% quantiles). These values are quite close, and the small discrepancy comes from the thermostat model error, unmeasured disturbances, neighbouring space temperature, etc. The blue distribution is based on an efficient setpoint scenario (i.e., Home $21.1^{\circ} \mathrm{C}$, Away $18.3^{\circ} \mathrm{C}$ ). Although this scenario is during the winter period, only a small amount of heating is required to maintain this setpoint. The red distribution indicates the energy consumption for a wasteful setpoint scenario (i.e., Home $26.1^{\circ} \mathrm{C}$, Away $24.0^{\circ} \mathrm{C}$ ). This is about 4 times higher than the current setpoint settings. It should be noted that in this building, the heating energy consumption in a unit is affected by the neighbouring spaces. For example, without any heating, the unit's temperature is maintained near $20^{\circ} \mathrm{C}$ during the winter because hallway and adjacent neighbours are all conditioned. Also, the location of thermostat in Figure 1 can explain this. The thermostat is far away from the building's exterior wall, so the average indoor temperature could be lower than the thermostat temperature. Finally, when the setpoint is not met for a certain time (30 minutes) or the outdoor temperature is low, the auxiliary electric heater is used instead of the heat pump. This leads to extra energy consumption. For example, in wasteful setpoint scenario, the heating energy consumption is very large because the rate of temperature increase becomes slower when the indoor temperature is higher than the neighbouring spaces, and this leads to extra energy consumption due to continuous operation of the auxiliary heater.

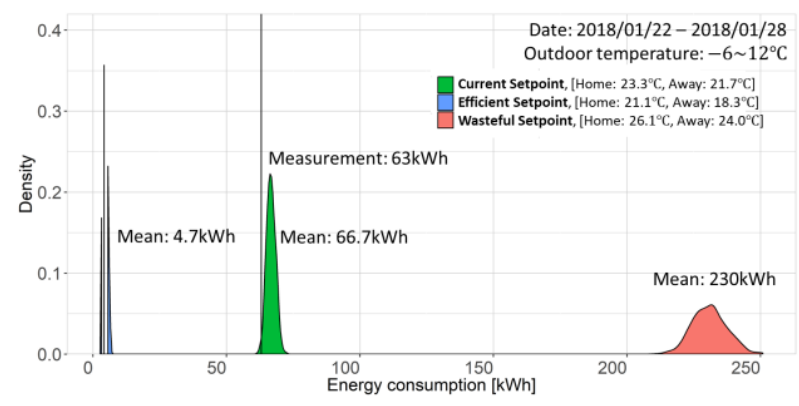

Figure 13. Predicted energy consumption with uncertainty

\section{Conclusions}

In this paper, we presented a data-driven modelling approach to predict the energy consumption with a new thermostat behaviour (setpoint schedule) in a multifamily residential building. The online grey-box model captures the unobserved building boundary conditions and evolution of parameters by using Liu-West particle filter. The Bayesian sequential update feature of this model allows estimation of the energy consumption based on a new setpoint schedule, and it can be used for real-time eco-feedback design.

\section{Acknowledgements}

This work was funded by the National Science Foundation under Grant No. 1737591 and the Big Ideas Challenge program at Purdue University. Any opinions, findings, and conclusions or recommendations expressed in this material are those of the authors and do not necessarily reflect the views of the National Science Foundation.

\section{References}

Alam, M., Rogers, A., Scott, J., Ali, K., \& Auffenberg, F. (2018). Applying extended Kalman filters to adaptive thermal modelling in homes. Advances in Building Energy Research, 12(1), 48-65. https://doi.org/10.1080/17512549.2017.1325398

Bourassa, N. J., Rainer, L., Mills, E., \& Glickman, J. (2012). The Home Energy Scoring Tool: A Simplified Asset Rating for Single Family Homes. 2012 ACEEE Summer Study on Energy Efficiency in Buildings, (12), 34-46.

Ehrhardt-Martinez, K. (2015). Behaviour wedge profiles for cities. ECEEE SUMMER STUDY PROCEEDINGS, 691-702.

EIA. (2015). Residential Energy Consumption Survey (RECS). U.S. Energy Information Administration.

Ellis, M. J., \& Alanqar, A. (2018). Formulation and Application of an Economic Model Predictive Control Scheme for Connected Thermostats. 5th International High Performance Buildings Conference at Purdue, 3194. 1-10.

Ford, R., Pritoni, M., Sanguinetti, A., \& Karlin, B. (2017). Categories and functionality of smart home technology for energy management. Building and Environment, 123, 543-554. https://doi.org/10.1016/j.buildenv.2017.07.020

Fux, S. F., Ashouri, A., Benz, M. J., \& Guzzella, L. (2014). EKF based self-adaptive thermal model for a passive house. Energy and Buildings, 68(PART C), $811-817$. https://doi.org/10.1016/j.enbuild.2012.06.016

Ham, S. woo, \& Karava, P. (2018). Identifying Peer Groups in a Multifamily Residential Building for Eco-Feedback Design. In International High Performance Buildings Conference (p. Paper 319). Retrieved

from 
https://docs.lib.purdue.edu/ihpbc/319

Hammerstrom, D. J., Ambrosio, R., Carlon, T. A., DeSteese, J. G., Horst, G. R., Kajfasz, R., ... Thompson, S. E. (2007). Pacific Northwest GridWiseTM Testbed Demonstration Projects; Part I. Olympic Peninsula Project. United States. https://doi.org/10.2172/926113

Jain, R. K., Taylor, J. E., \& Peschiera, G. (2012). Assessing eco-feedback interface usage and design to drive energy efficiency in buildings. Energy and Buildings, 48 , $8-17$ https://doi.org/10.1016/j.enbuild.2011.12.033

Karlin, B., Zinger, J. F., \& Ford, R. (2015). The effects of feedback on energy conservation: A meta-analysis. Psychological Bulletin. Karlin, Beth: University of California, Irvine, 5548 Social \& Behavioral Science Gateway, Irvine, CA, US, 92697-7075, bkarlin@uci.edu: American Psychological Association. https://doi.org/10.1037/a0039650

Liu, J., \& West, M. (2001). Combined Parameter and State Estimation in Simulation-Based Filtering. In A. Doucet, N. de Freitas, \& N. Gordon (Eds.), Sequential Monte Carlo Methods in Practice (pp. 197-223). New York, NY: Springer New York. https://doi.org/10.1007/978-1-4757-3437-9_10

Mullen, K. M., Ardia, D., Gil, D. L., Windover, D., \& Cline, J. (2011). DEoptim: An R Package for Global Optimization by Differential Evolution. Journal of
Statistical Software; Vol 1, Issue 6 (2011) . https://doi.org/10.18637/jss.v040.i06

Pisharoty, D., Yang, R., Newman, M. W., \& Whitehouse, K. (2015). ThermoCoach: Reducing Home Energy Consumption with Personalized Thermostat Recommendations. In Proceedings of the $2 \mathrm{Nd}$ ACM International Conference on Embedded Systems for Energy-Efficient Built Environments (pp. 201-210). New York, NY, USA: ACM. https://doi.org/10.1145/2821650.2821671

Radecki, P., \& Hencey, B. (2012). Online building thermal parameter estimation via Unscented Kalman Filtering. In 2012 American Control Conference (ACC) (pp. 3056-3062). https://doi.org/10.1109/ACC.2012.6315699

Roth, J., \& Jain, R. K. (2018). Data-Driven, Multi-metric, and Time-Varying (DMT) Building Energy Benchmarking Using Smart Meter Data BT Advanced Computing Strategies for Engineering. In I. F. C. Smith \& B. Domer (Eds.) (pp. 568-593). Cham: Springer International Publishing.

Siemann, M. J. (2013). Performance and applications of residential building energy grey-box models. Ph.D. dissertation, University of Maryland.

Simon, D. (2006). Optimal state estimation: Kalman, H infinity, and nonlinear approaches. John Wiley \& Sons. 